\title{
Effects of weekly regrouping of prepartum dairy cows on metabolic, health, reproductive, and productive parameters
}

\author{
P. R. B. Silva, ${ }^{\star} \dagger$ J. G. N. Moraes, ${ }^{*} \dagger$ L. G. D. Mendonça, ${ }^{*}$ A. A. Scanavez, ${ }^{*}$ G. Nakagawa, ${ }^{\star}$ J. Fetrow, ${ }^{*}$ \\ M. I. Endres, $\dagger$ and R. C. Chebel ${ }^{*} \dagger^{1}$ \\ *Department of Veterinary Population Medicine, and \\ †Department of Animal Science, University of Minnesota, St. Paul 55108
}

\begin{abstract}
The objectives of the current experiment were to determine the effect of 2 prepartum grouping strategies on the health, metabolic, reproductive, and productive parameters of dairy cows. Jersey cows enrolled in the experiment at $253 \pm 3 \mathrm{~d}$ of gestation $(\mathrm{d} 0=$ calving $)$ were balanced for parity and projected 305-d mature equivalent and assigned to 1 of 2 treatments. Cows assigned to the traditional (TRD; $\mathrm{n}=6$ replicates with a total of 308 cows) treatment were moved to the study pen as a group of 44 cows and weekly thereafter groups of 2 to 15 cows were moved to the study pen to reestablish stocking density. Cows assigned to the all-in-allout (AIAO; $\mathrm{n}=6$ replicates with a total of 259 cows) treatment were moved to the study pen in groups of 44 cows, but no new cows entered the AIAO pen until the end of the replicate. At the end of each replicate, a new TRD and AIAO group started but pens were switched. Cows were milked thrice daily and monthly milk yield, fat and protein contents, and somatic cell count data were recorded up to $305 \mathrm{~d}$ postpartum. Plasma nonesterified fatty acid concentration was measured weekly from d $-18 \pm 3$ to $24 \pm 3$ and plasma $\beta$-hydroxybutyrate was measured weekly from d $3 \pm 3$ to $24 \pm 3$. Cows were examined on $\mathrm{d} 1,4 \pm 1,7 \pm 1$, $10 \pm 1$, and $13 \pm 1$ for diagnosis of uterine diseases and had their ovaries scanned by ultrasound on $\mathrm{d} 39 \pm 3$ and $53 \pm 3$ to determine resumption of ovarian cycles. Average stocking density was reduced for the AIAO (71.9\%) treatment compared with the TRD (86.9\%) treatment. Treatment did not affect the incidences of retained fetal membranes $(\mathrm{TRD}=10.9, \mathrm{AIAO}=$ $11.6 \%)$, metritis $(\mathrm{TRD}=16.7, \mathrm{AIAO}=19.8 \%)$, and acute metritis $(\mathrm{TRD}=1.7, \mathrm{AIAO}=3.6 \%)$. Concentrations of nonesterified fatty acids $(\mathrm{TRD}=80.4 \pm 8.2$, $\mathrm{AIAO}=62.9 \pm 8.5 \mu \mathrm{mol} / \mathrm{L})$ and $\beta$-hydroxybutyrate $(\mathrm{TRD}=454.4 \pm 10.9, \mathrm{AIAO}=446.1 \pm 11.1 \mu \mathrm{mol} / \mathrm{L})$ were not different between treatments. Percentages of
\end{abstract}

Received December 8, 2012.

Accepted March 11, 2013

${ }^{1}$ Corresponding author: chebe002@umn.edu cows that resumed ovarian cycles by d $39 \pm 3$ (TRD $=70.8, \mathrm{AIAO}=63.1 \%)$ and $53 \pm 3(\mathrm{TRD}=90.1$, AIAO $=90.2 \%)$ were not different between treatments. Similarly, treatment had no effect on rate of removal from the herd $\{\mathrm{TRD}=$ referent, AIAO [(adjusted hazard ratio $(95 \%$ confidence interval $)]=0.85(0.63,1.15)\}$ or rate of pregnancy $[\mathrm{TRD}=$ referent, $\mathrm{AIAO}=1.07$ $(0.88,1.30)]$. Finally, treatment did not affect energycorrected milk yield $(\mathrm{TRD}=34.4 \pm 0.6$, AIAO $=34.3$ $\pm 0.7 \mathrm{~kg} / \mathrm{d}$ ). In conditions of adequate feed bunk space, the AIAO treatment did not improve health, metabolic, reproductive, or productive parameters compared with the TRD treatment.

Key words: lactating dairy cow, transition period, grouping strategy

\section{INTRODUCTION}

Cows are social animals and are affected by interactions with herd-mates. Regrouping of dairy cows is used in dairy operations to maintain homogeneous groups of cows in terms of gestation stage, reproductive status, or milk yield to optimize management (i.e., nutritional management). In most herds with dry periods of 50 to $60 \mathrm{~d}$, cows are grouped into far-off dry cow pens (from dry-off to approximately $28 \mathrm{~d}$ before expected calving date) and close-up dry cow pens (from approximately $27 \mathrm{~d}$ before expected calving date to calving). In large dairy operations, cows from the far-off pens are usually moved to the close-up pens weekly, which has been suggested to result in weekly disruption of social interactions and, for many cows, disruption of social interactions in the last days before parturition (Cook and Nordlund, 2004).

Constant regrouping of cows changes the hierarchical order among them, forcing cows to reestablish social relationships through physical and nonphysical interactions and exacerbating aggressive and submissive behaviors (Zelena et al., 1999; von Keyserlingk et al., 2008). Cows had reduced feeding time, greater rate of displacement from the feed bunk and stalls, and reduced milk yield within $24 \mathrm{~h}$ following regrouping (von Keyserlingk et al., 2008). Furthermore, Schirmann et al. (2011) demonstrated that regrouping of prepartum cows housed 
in pens with 1 feed bin for every 2 cows and 1 stall per cow resulted in reduced feed intake compared with feed intake before movement. Although the question has not yet been definitively answered, some researchers have suggested that cows may require 3 to $14 \mathrm{~d}$ after regrouping to reestablish social stability to preregrouping levels (Grant and Albright, 2001). In the study by von Keyserlingk et al. (2008), however, the changes in behavior observed after regrouping were transitory, and behavioral patterns returned to preregrouping values within hours or the day after regrouping..

During the peripartum period cows are predisposed to reduced DMI, negative energy balance, and immune suppression (Goff and Horst, 1997). Associations among reduced DMI and feeding time in the prepartum period and metritis have been observed (Hammon et al., 2006; Huzzey et al., 2007). Weekly regrouping of prepartum cows has been suggested to increase the risk for postpartum diseases and reduced productivity because of the observed behavioral changes associated with regrouping that could result in reduced DMI and increased stress (Cook and Nordlund, 2004). In a recent experiment, Coonen et al. (2011) demonstrated that Holstein cows housed in a stable pen with no entry of new cows in the prepartum period (14-28 d before expected calving date) had similar DMI and NEFA concentrations during the prepartum period and similar milk yield in the first 30 DIM compared with cows housed in pens with entry of new cows twice weekly in the last 14 to $28 \mathrm{~d}$ before expected calving date. However, this study had an insufficient number of cows to evaluate health and reproductive performance and milk yield was not measured throughout the entire lactation.

The hypothesis of the current experiment was that cows submitted to an all-in-all-out (AIAO) prepartum grouping strategy (no entry of new cows in the prepartum pen) would have reduced incidence of health and metabolic disorders in the periparturient period compared with cows submitted to a traditional (TRD) prepartum strategy (weekly entry of new cows in the prepartum pen). Furthermore, we hypothesized that reduced frequency of regrouping (AIAO vs. TRD) during the prepartum period would result in increased milk yield, reduced death or culling rates, and increased pregnancy rates. The objectives of the current experiment were to compare health, metabolic, reproductive, and productive parameters of lactating dairy cows submitted to the AIAO or TRD prepartum grouping strategy.

\section{MATERIALS AND METHODS}

\section{Cows, Facilities, Management, and Nutrition}

The experiment was conducted from February 2011 to October 2012 with cows enrolled from February 2011 to August 2011 and calving occurring from February 2011 to October 2011. Prepartum Jersey cows $(\geq 1$ lactation) were enrolled in the experiment at $253 \pm 3$ $\mathrm{d}$ of gestation $(\mathrm{d} 0=$ calving $)$. During the prepartum period cows were housed in 1 of 2 freestall pens with 44 stalls and 48 headlocks that were identical in size (31.7 $\left.\times 11 \mathrm{~m}, 347.8 \mathrm{~m}^{2}\right)$ and design. Stalls measured $230 \mathrm{~cm}$ (length) $\times 107 \mathrm{~cm}($ width $) \times 114 \mathrm{~cm}$ (neck rail height) and headlocks measured $0.61 \mathrm{~m} /$ headlock. Pens had 2 water troughs at each end of the pen that measured 366 $\mathrm{cm}$ by $56 \mathrm{~cm}$. The barn was cross-ventilated and had artificial lighting ( $8 \mathrm{~h}$ of light and $16 \mathrm{~h}$ of dark). Temperature and relative humidity were recorded hourly in each study pen throughout the experiment and daily average temperature-humidity index was calculated for each pen. During the prepartum period and at the start of each replicate the target stocking densities were $100 \%$ of stalls and $91.6 \%$ of headlocks. In the freestall, including stalls and alleys, $7.9 \mathrm{~m}^{2} /$ cow was allotted.

As cows demonstrated signs of calving (discomfort, restlessness, tail twitching, and exteriorization of the allantoic sac through the vulva) cows were moved to a box stall. During the immediate postpartum period (d 1 to $21 \pm 3$ ) all cows were housed in the same freestall pen with 240 stalls and 260 headlocks. Five water troughs were available per pen that measured $366 \mathrm{~cm}$ by $56 \mathrm{~cm}$. The barn was cross-ventilated and had artificial lighting ( $16 \mathrm{~h}$ of light and $8 \mathrm{~h}$ of dark). From d 1 to $21 \pm 3$, pens were stocked at $100 \%$ and $91.6 \%$ of stalls and headlocks, respectively. From d 21 \pm 3 until diagnosis of pregnancy $66 \pm 3 \mathrm{~d}$ after AI cows were housed in cross-ventilated freestall barns with 240 stalls and 260 headlocks. From the second pregnancy diagnosis to the end of the lactation cows were housed in a nearby naturally ventilated freestall dairy with 260 stalls and 280 headlocks. Stocking density from d 21 to the end of lactation varied between 110 and $120 \%$ of headlocks and between 119 and $130 \%$ of stalls.

From enrollment to calving, all cows were fed the same TMR once a day. From d 1 until the time of the second pregnancy diagnosis cows were fed the same TMR and from the time of the second pregnancy diagnosis to dry-off cows were fed the same TMR. Feed was delivered twice a day $(70 \%$ in the a.m. and $30 \%$ in the p.m.) for lactating cows. Composition of TMR fed in the prepartum and immediate postpartum period ( $\mathrm{d} 1$ to $21 \pm 3$ ) are described in Table 1.

\section{Treatments}

At enrollment all cows were $\geq 1$ lactation. Cows were balanced for parity ( 1 or $\geq 2$ lactation) and projected 305-d mature equivalent milk yield at enrollment and were assigned to 1 of the 2 study pens. Treatment ap- 
plied to the study pens in the first replicate was determined by a coin toss. Cows assigned to the TRD ( $\mathrm{n}=6$ replicates with a total of 308 cows) grouping strategy were moved to the prepartum pen as a group of 44 cows. Weekly thereafter, groups of 2 to 15 cows (median $=9$ cows) were moved to the TRD pen to reestablish the desired stocking density (100\% of stalls and $91.6 \%$ of headlocks). Cows assigned to the AIAO ( $\mathrm{n}=6$ replicates with a total of 259 cows) grouping strategy were moved to the prepartum pen in groups of 44 cows (stocking density of $100 \%$ of stalls and $91.6 \%$ of headlocks), but no new cows were added to the AIAO pen until the end of the replicate. At the end of each replicate, a new TRD and AIAO group started but pens were switched to avoid location bias, even though pens were identical in design and had similar temperature and humidity throughout the study (data not shown). Cows in the AIAO that had not calved by the end of the replicate $(\mathrm{n}=18)$ were moved to a different pen of approximately 156 cows, but the TMR offered was the same. The data of these AIAO cows that had not calved by the end of the replicate were included in the statistical analysis to compare the AIAO and TRD prepartum grouping strategies. Furthermore, the performance of these AIAO cows that had not calved by the end of the replicate and had to be moved to a different pen was compared with that of AIAO cows that calved before the end of the replicate and had no pen movement during the close-up period.

Six replicates were completed in total. Thus, each pen had the TRD and AIAO treatments thrice during the experiment. The number of cows in each pen was counted daily during the prepartum period, and daily stocking density was calculated by the number of cows in the pen divided by the number of stalls.

\section{Body Condition and Locomotion Score}

At enrollment and on $\mathrm{d} 1 \pm 1,28 \pm 3$, and $56 \pm 3$ all cows were scored for body condition $(1=$ emaciated and $5=$ obese; 0.25 unit increments as described by Ferguson et al., 1994) and locomotion $(1=$ normal locomotion and $5=$ severely lame; as described by Sprecher et al., 1997).

\section{Blood Sampling and Analysis of Metabolites in Plasma}

Blood samples were collected from all cows on $\mathrm{d}-18$ $\pm 3,-11 \pm 3,-4 \pm 3,3 \pm 3,10 \pm 3,17 \pm 3$, and 24 \pm 3 from the coccygeal vein or artery immediately after feeding while cows were restrained in self-locking headlocks. The needles used were 22 gauge and 1-in. long and samples were collected into evacuated tubes con-
Table 1. Composition of TMR offered to prepartum ( $\mathrm{d}-24 \pm 3$ to 0 ; d $0=$ calving) and postpartum (d 1 to $21 \pm 3$ ) cows

\begin{tabular}{lcc}
\hline $\begin{array}{l}\text { Item, \% of DM } \\
\text { (unless otherwise noted) }\end{array}$ & Prepartum & Postpartum \\
\hline $\mathrm{DM}, \%$ & 44.9 & 49.6 \\
$\mathrm{NE}$, Mcal/kg & 1.31 & 1.61 \\
$\mathrm{CP}$ & 13.43 & 16.20 \\
$\mathrm{ADF}$ & 32.90 & 21.75 \\
$\mathrm{NDF}$ & 44.83 & 31.11 \\
Ether extract & 2.43 & 4.04 \\
Ash & 10.43 & 7.50 \\
Calcium & 1.44 & 0.87 \\
Phosphorus & 0.41 & 0.49 \\
Magnesium & 0.41 & 0.34 \\
Potassium & 1.17 & 1.43 \\
Sulfur & 0.34 & 0.27 \\
Sodium & 0.13 & 0.37 \\
Chlorine & 1.21 & 0.38 \\
\hline
\end{tabular}

taining K2 EDTA (Becton Dickinson Vacutainer Systems, Franklin Lakes, NJ). The utmost care was taken to minimize stress during sample collection. Tubes were placed in ice until centrifugation for plasma separation $\left(1,200 \times g\right.$ for $15 \mathrm{~min}$ at $\left.4^{\circ} \mathrm{C}\right)$. Plasma was aliquoted into microcentrifuge tubes and stored at $-32^{\circ} \mathrm{C}$ until analysis.

Samples collected weekly from d $-18 \pm 3$ to $24 \pm$ 3 were analyzed for concentrations of NEFA using a colorimetric assay (Wako Chemicals USA, Richmond, VA; Ballou et al., 2009). Concentrations of BHBA were determined enzymatically (Ranbut, Randox Laboratories, Antrim, UK; Ballou et al., 2009) from samples collected weekly from d $3 \pm 3$ to $24 \pm 3$. A plate reader (Spectramax 340, Molecular Devices, Sunnyvale, CA) was used to measure the absorbance for the colorimetric and enzymatic assays. Control serum (Randox Control Sera, Randox Laboratories) was used for the NEFA and BHBA assays. The intra-assay CV were 5.1 and $7.9 \%$ for the NEFA and BHBA assays, respectively. The interassay CV were 9.2 and $10.8 \%$ for the NEFA and BHBA assays, respectively.

\section{Clinical Examination and Definitions of Diseases}

All cows were examined on d 1, $4 \pm 1,7 \pm 1,10 \pm 1$, and $13 \pm 1$ for the diagnosis of retained fetal membrane, metritis, and acute metritis. Retained fetal membrane was defined as retention of a fetal membrane past $24 \mathrm{~h}$ postpartum. Metritis was defined as cows with watery, pink or brown, and fetid uterine discharge. Cows with symptoms of metritis and rectal temperature $>39.5^{\circ} \mathrm{C}$, or anorectic, or depressed were considered to have acute metritis (LeBlanc, 2010). All cows were observed once daily for displacement of abomasum (DA) and thrice daily for mastitis throughout their lactation. Data regarding incidence of DA and mastitis from d 0 to 60 are reported herein. 
During wk 1 of each replicate, a subgroup of TRD and AIAO cows ( $\mathrm{n}=34$ /treatment) was selected randomly for intensive blood sampling and evaluation of innate and humoral immune responses (Silva et al., 2012). On d $35 \pm 3$, the subgroup of cows used to evaluate innate and humoral immune responses was examined for subclinical endometritis $(\geq 10 \%$ of cells in the uterine cytology were polymorphonuclear leukocytes; Kasimanickam et al., 2004) using the cytobrush technique (Cytobrush Plus, Cooper Surgical Inc., Trumbull, CT). After sample collection, the cytobrush was rolled onto a clean glass slide, which was stained with modified Wright-Giemsa stain (Protocol-Hema3, Biochemical Sciences, Swedesboro, NJ). Slides were evaluated twice at $400 \times$ magnification by one examiner who was blinded to the treatments. The same subgroup of cows was examined for clinical endometritis (exudate consisting of $\geq 50 \%$ of pus) using the Metricheck device (Simcro, Hamilton, New Zealand; McDougall et al., 2007) on d $35 \pm 3$.

\section{Resumption of Ovarian Cycles Postpartum}

All cows had their ovaries examined by ultrasound ( 5 $\mathrm{MHz}$, Ibex Lite, E. I. Medical Imaging, Loveland, CO) on d $39 \pm 3$ and $53 \pm 3$. Cows with a corpus luteum (CL) on d $39 \pm 3$ were considered to have resumed ovarian cycles by d $39 \pm 3$. Cows without a CL on d 39 \pm 3 and with a CL on d $53 \pm 3$ were considered to have resumed ovarian cycles by d $53 \pm 3$. Cows without a CL on d $39 \pm 3$ and $53 \pm 3$ were considered to be anovular.

\section{Production Parameters}

Cows were milked thrice daily. Monthly, milk yield, milk fat and protein contents, and SCC were recorded for individual cows during the official Dairy Herd Improvement Association test. Data regarding milk yield, milk fat and protein contents, and SCC were collected from d 0 to 305. Energy-corrected milk was calculated for each cow using the formula (Orth, 1992)

$$
\begin{gathered}
\operatorname{ECM}(\mathrm{kg})=[(\mathrm{kg} \text { of milk }) \times 0.327]+[(\mathrm{kg} \text { of fat }) \\
\times 12.95]+[(\mathrm{kg} \text { of protein }) \times 7.2] .
\end{gathered}
$$

All cows received recombinant bST (500 mg of Posilac; Elanco Animal Health, Greenfield, IN) every $10 \mathrm{~d}$ starting at $\mathrm{d} 57 \pm 3$ postpartum.

\section{Reproductive Parameters and Removal from the Herd}

All cows were subjected to the same reproductive program. Cows were presynchronized with 2 injections of $\mathrm{PGF}_{2 \alpha}$ on $\mathrm{d} 39 \pm 3$ and $53 \pm 3$. Cows were inseminated if observed in estrus after d 50. Cows not observed in estrus were enrolled in the Ovsynch56 protocol (GnRH, $\mathrm{PGF}_{2 \alpha} 7 \mathrm{~d}$ later, and $\mathrm{GnRH} 56 \mathrm{~h}$ later) on $\mathrm{d} 65 \pm 3$ and were inseminated at fixed time on $\mathrm{d} 75$ \pm 3 . Cows were examined for pregnancy $31 \pm 3 \mathrm{~d}$ after $\mathrm{AI}$ and pregnant cows were reexamined $66 \pm 3$ and 178 $\pm 3 \mathrm{~d}$ after AI. The percentage of cows receiving first AI in estrus, percentage of cows pregnant to first and second AI, percentage of cows with pregnancy loss from $31 \pm 3$ to $66 \pm 3 \mathrm{~d}$ after first and second AI, number of inseminations up to $\mathrm{d} 305$, and pregnancy rate up to d 305 were calculated. Cows were followed from d 0 to 305 to determine the percentage of cows removed (sold or dead) from the herd and the speed at which cows were removed from the herd.

\section{Statistical Analysis}

The experiment had a randomized switch back design with pen as the experimental unit. In the first replicate a coin was tossed to determine the treatment of each of the 2 study pens. In each of the replicates, cows were balanced for parity ( 1 or $\geq 2$ lactation) and projected $305-\mathrm{d}$ mature equivalent milk yield and were assigned to 1 of the 2 study pens. Based on retrospective data from the collaborating herd, the expected standard deviation of monthly milk yield during an entire lactation, when comparing several cohorts of approximately 44 cows, was $1.63 \mathrm{~kg}$. Thus, sample size was calculated based on an expected standard deviation of average daily milk yield equal to $1.63 \mathrm{~kg} / \mathrm{d}$ and an expected difference in daily average milk yield during the lactation between the TRD and AIAO treatments of $2.5 \mathrm{~kg} / \mathrm{d}(\alpha=0.05$, $1-\beta=0.80)$.

Statistical analyses were conducted using SAS version 9.2 (SAS/STAT, SAS Inst. Inc., Cary, NC). Binomial data were analyzed by logistic regression using the GLIMMIX procedure and the binary distribution. Continuous data were analyzed by ANOVA using the MIXED procedure. In all models, treatment (TRD vs. AIAO), replicate (1-6), and the interaction between treatment and replicate were included as a fixed effect. Pen was included as the random effect. Cows were nested within replicate and pen and treatment was nested within pen and replicate. The repeated statement was used for analysis of repeated measurements, the structure of covariance (autoregressive, unstructured, or compound symmetry) was chosen according to the Bayesian Akaike information criteria, and time and the interaction between treatment and time were included in the model as fixed effects.

The rates at which cows became pregnant and were removed from the herd were analyzed by Cox propor- 
tional hazard ratio using the PHREG procedure with removal of variables by a stepwise backward elimination process based on the Wald's statistics criterion when $P>0.10$. The model included treatment (TRD vs. AIAO), replicate (1-6), the interaction between treatment and replicate, and pen as fixed effects. Cow was used as the experimental unit in the Cox proportional hazard ratio analysis. Kaplan-Meier survival analysis, using the LIFETEST procedure, was used to compare the interval from enrollment to removal from the herd and from calving to establishment of pregnancy between treatments. Because the Kaplan-Meier survival analysis is a univariable analysis, we only present the calculated means to occurrence of the event. Statistical significance was defined as $P \leq 0.05$ and statistical tendencies as $0.05<P \leq 0.10$.

\section{RESULTS}

Three cows $(\mathrm{TRD}=1$ and $\mathrm{AIAO}=2)$ died before calving because of injury. At enrollment $(253 \pm 3 \mathrm{~d}$ of gestation), TRD and AIAO treatments were similar regarding the number of lactations $(\mathrm{TRD}=1.77 \pm 0.06$, $\mathrm{AIAO}=1.69 \pm 0.07$ lactations; $P=0.36)$, number of inseminations $(\mathrm{TRD}=2.09 \pm 0.20, \mathrm{AIAO}=2.06 \pm$ 0.21 inseminations; $P=0.92), 305$-d mature equivalent milk yield $(\mathrm{TRD}=9,906.3 \pm 360.2, \mathrm{AIAO}=9,878.4 \pm$ $363.8 \mathrm{~kg} ; P=0.96), \mathrm{BCS}(\mathrm{TRD}=3.06 \pm 0.08, \mathrm{AIAO}$ $=3.02 \pm 0.08 ; P=0.72$ ) , and percentage of cows with locomotion score of $3(\mathrm{TRD}=0.65, \mathrm{AIAO}=1.93 \% ; P$ $=0.78)$. At enrollment, no cows had a locomotion score $>3$. Upon calving, gestation length was similar between treatments $(\mathrm{TRD}=281.3 \pm 0.5, \mathrm{AIAO}=280.3 \pm 0.5$ $\mathrm{d} ; P=0.19)$. Incidences of male calves $(\mathrm{TRD}=49.2$, AIAO $=47.3 \% ; P=0.71)$ and twins $(\mathrm{TRD}=2.6$, AIAO $=3.5 \% ; P=0.55)$ were not different between treatments.

Daily average stocking density in the prepartum pens was greater $(P<0.01)$ for TRD $(86.9 \%)$ than AIAO $(71.9 \%)$ treatment. Furthermore, the interaction between treatment and day after the start of a new replicate affected $(P<0.01)$ the daily average stocking density (Figure 1).

\section{Incidence of Diseases Postpartum}

No differences were observed between treatments regarding the incidence of periparturient diseases (Table 2). Similarly, TRD and AIAO treatments had similar incidences of DA and mastitis in the first $60 \mathrm{~d}$ postpartum (Table 2). Percentages of cows with locomotion score $>2$ were not different between treatments (Table 2 ). Similarly, treatment did not affect the likelihood of cows being removed from the herd within $60 \mathrm{~d}$

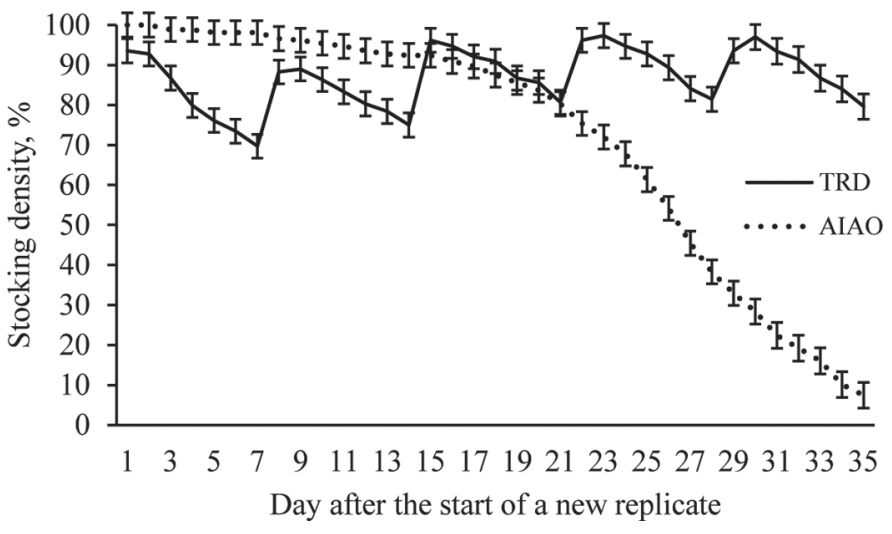

Figure 1. Effect of prepartum grouping strategy on stocking density of prepartum pens. The traditional prepartum grouping strategy (TRD) had weekly entry of new cows into the prepartum pen, and the all-in-all-out (AIAO) prepartum grouping strategy had no entry of new cows in the prepartum pen. Target stocking density was $100 \%$ of stalls and $91.6 \%$ of headlocks and $7.9 \mathrm{~m}^{2} /$ cow. The AIAO treatment resulted in reduced $(P<0.01)$ stocking density compared with the TRD treatment, and the interaction between treatment and day after the start of the new replicate $(P<0.01)$ also affected stocking density.

postpartum (Table 2). The rate at which cows in the AIAO treatment were removed from the herd adjusted hazard ratio $($ AHR $)(95 \%$ CI $)=0.85(0.63,1.15)]$ did not $(P=0.29)$ differ from that of cows in the TRD treatment. The mean \pm SEM intervals from calving to removal from the herd were $251.3 \pm 5.3 \mathrm{~d}$ for the TRD treatment and $255.8 \pm 5.5 \mathrm{~d}$ for the AIAO treatment (Figure 2).

\section{BCS and Metabolic Parameters}

Body condition score was not affected by treatment (Figure 3). Concentrations of NEFA (TRD $=80.4 \pm$ $8.2, \mathrm{AIAO}=62.9 \pm 8.5 \mu \mathrm{mol} / \mathrm{L})$ and BHBA $(\mathrm{TRD}=$ $454.4 \pm 10.9, \mathrm{AIAO}=446.1 \pm 11.1 \mu \mathrm{mol} / \mathrm{L})$ were not different between treatments. Figures 4 and 5 depict the raw average concentrations of NEFA and BHBA, respectively, of cows in the TRD and AIAO treatments.

\section{Resumption of Ovarian Cycles Postpartum and Reproductive Parameters}

The percentages of cows diagnosed with a CL on d 39 \pm 3 and $53 \pm 3$ was not different between treatments (Table 3). Similarly, the likelihood of cows being inseminated on estrus for the first time after parturition was not different between treatments (Table 3). Consequently, average days postpartum at first insemination was not different $(P=0.63)$ between treatments (TRD $=65.1 \pm 0.8, \mathrm{AIAO}=65.6 \pm 0.9 \mathrm{~d}$ ). The percentages of cows that were diagnosed as pregnant $31 \pm 3$ and 66 $\pm 3 \mathrm{~d}$ after first postpartum AI were not different be- 
Table 2. Effects of prepartum grouping strategy (TRD vs. AIAO) ${ }^{1}$ on incidence of postpartum health disorders, lameness, and removal from the herd within $60 \mathrm{~d}$ postpartum

\begin{tabular}{|c|c|c|c|c|}
\hline Item & $\mathrm{TRD},{ }^{1} \%$ & $\mathrm{AIAO},{ }^{1} \%$ & $\operatorname{AOR}(95 \% \mathrm{CI})^{2}$ & $P$-value \\
\hline Metritis & 16.7 & 19.8 & $1.23(0.75,2.02)$ & 0.37 \\
\hline Acute metritis & 1.7 & 3.6 & $2.18(0.58,8.19)$ & 0.22 \\
\hline Endometritis at $35 \mathrm{~d}$ postpartum ${ }^{3}$ & 10.3 & 10.3 & $0.95(0.13,6.79)$ & 0.96 \\
\hline Displacement of abomasum & 3.2 & 1.7 & $0.51(0.10,2.58)$ & 0.38 \\
\hline Mastitis within $60 \mathrm{~d}$ postpartum & 13.8 & 11.3 & $0.77(0.38,1.59)$ & 0.45 \\
\hline Lame at $56 \pm 3$ DIM & 9.1 & 6.0 & $0.64(0.28,1.46)$ & 0.25 \\
\hline Removal from the herd within $60 \mathrm{~d}$ postpartum & 9.1 & 8.9 & $0.98(0.49,1.93)$ & 0.94 \\
\hline
\end{tabular}

${ }^{1}$ Traditional prepartum grouping strategy $(\mathrm{TRD})=$ weekly entry of new cows into the prepartum pen; all-in-all-out prepartum grouping strategy $(\mathrm{AIAO})=$ no entry of new cows in the prepartum pen. Target stocking density was $100 \%$ of stalls and $91.6 \%$ of headlocks and $7.9 \mathrm{~m}^{2} /$ cow. ${ }^{2} \mathrm{AOR}=$ adjusted odds ratio. TRD treatment was set as referent.

${ }^{3}$ Incidence of subclinical endometritis and clinical endometritis are based on a subgroup of cows $(\mathrm{n}=34$ per treatment) randomly selected on wk 1 of each replicate that was used for evaluation of innate and humoral immune responses (Silva et al., 2012).

tween treatments (Table 3). Incidence of pregnancy loss between $31 \pm 3$ and $66 \pm 3 \mathrm{~d}$ after the first postpartum AI was not different between treatments (Table 3). The interval from first to second postpartum AI was not $(P$ $=0.82)$ different between the TRD $(28.0 \pm 0.9 \mathrm{~d})$ and AIAO $(28.3 \pm 1.0 \mathrm{~d})$ treatments. The percentages of cows diagnosed as pregnant $31 \pm 3$ and $66 \pm 3 \mathrm{~d}$ after the second postpartum AI were not different between TRD and AIAO treatments (Table 3). The number of inseminations up to $305 \mathrm{~d}$ postpartum was not $(P=$ $0.67)$ different between the TRD $(2.3 \pm 0.2)$ and AIAO $(2.4 \pm 0.2)$ treatments. Finally, the AHR for pregnancy was not $(P=0.49)$ different between the AIAO [AHR

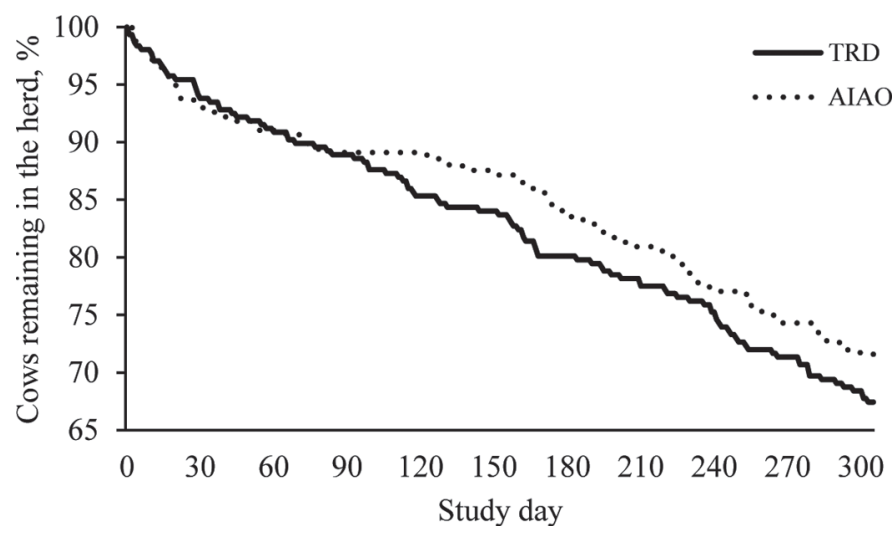

Figure 2. Survival analysis of interval from calving to removal from the herd according to prepartum grouping strategy. The adjusted hazard ratio (AHR) for removal from the herd was not $(P=0.29)$ different between the all-in-all-out (AIAO) prepartum grouping strategy $[\operatorname{AHR}(95 \% \mathrm{CI})=0.85(0.63,1.15)]$ and traditional $(\mathrm{TRD})$ prepartum grouping strategy treatments. The TRD group had weekly entry of new cows into the prepartum pen, and AIAO had no entry of new cows in the prepartum pen. Target stocking density was $100 \%$ of stalls and $91.6 \%$ of headlocks and $7.9 \mathrm{~m}^{2} /$ cow. The mean \pm SEM intervals from calving to removal from the herd were $251.3 \pm 5.3 \mathrm{~d}$ for the TRD treatment and $255.8 \pm 5.5 \mathrm{~d}$ for the AIAO treatment.
$(95 \% \mathrm{CI})=1.07(0.88,1.30)]$ and TRD treatments. The mean \pm SEM intervals from calving to establishment of pregnancy were $136.9 \pm 5.2 \mathrm{~d}$ for the TRD treatment and $132.7 \pm 5.0 \mathrm{~d}$ for the AIAO treatment (Figure 6).

\section{Milk Yield and Milk Components}

Average daily milk yield from calving to $305 \mathrm{~d}$ postpartum was not different between treatments (Table 4). Similarly, fat and protein yields were not different between TRD and AIAO cows (Table 4). Consequently, yields of $3.5 \%$ FCM and ECM were not different between treatments (Table 4; Figure 7). Finally, linear SCC was not different between TRD and AIAO treatments (Table 4).

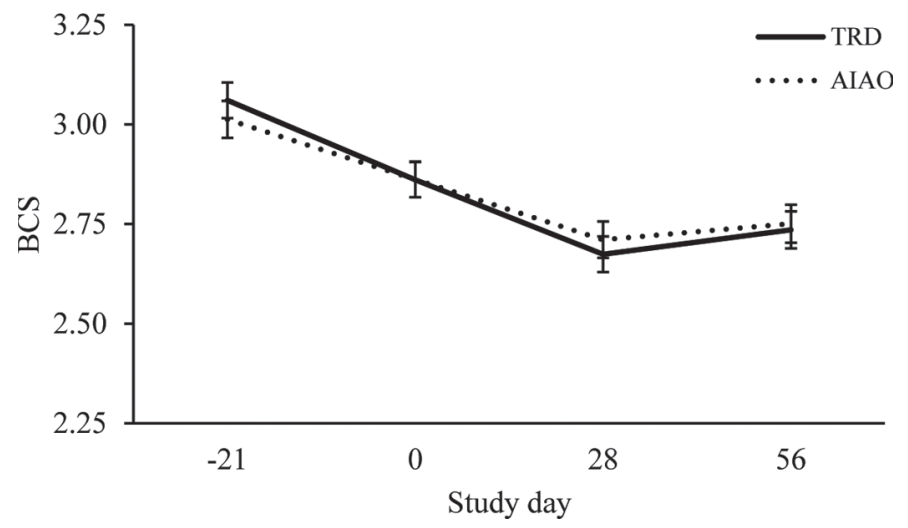

Figure 3. Body condition score of cows enrolled in the traditional prepartum grouping strategy (TRD) and all-in-all-out (AIAO) prepartum grouping strategy treatments. The TRD had weekly entry of new cows into the prepartum pen, and AIAO had no entry of new cows in the prepartum pen. Target stocking density was $100 \%$ of stalls and $91.6 \%$ of headlocks and $7.9 \mathrm{~m}^{2} /$ cow. Treatment $(P=0.99)$ and the interaction between treatment and study day $(P=0.14)$ did not affect BCS throughout the study. 


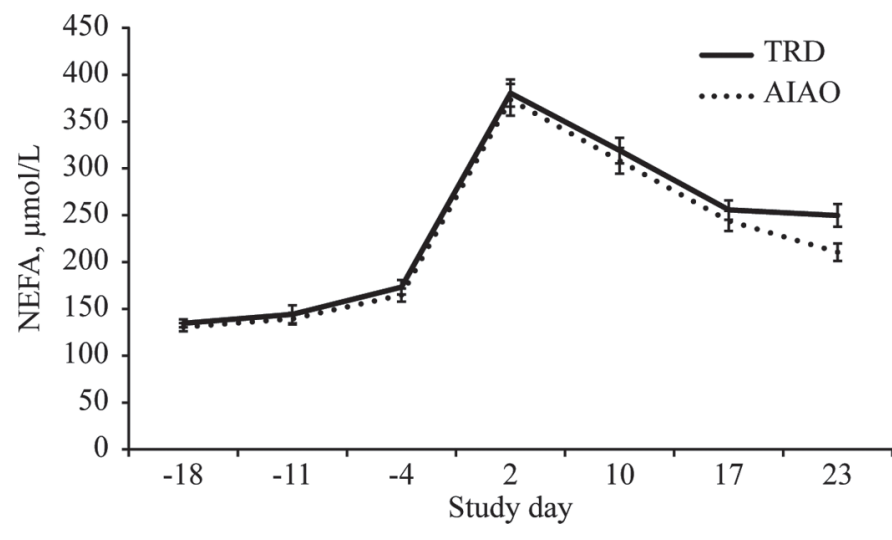

Figure 4. Raw means of plasma concentrations of NEFA of cows submitted to the traditional prepartum grouping strategy (TRD) and all-in-all-out (AIAO) prepartum grouping strategy. Bars represent the SEM calculated using the raw means. The TRD had weekly entry of new cows into the prepartum pen, and AIAO had no entry of new cows in the prepartum pen. Target stocking density was $100 \%$ of stalls and $91.6 \%$ of headlocks and $7.9 \mathrm{~m}^{2} /$ cow. No effects of treatment $(P=0.17)$ and of the interaction between treatment and study day $(P=0.11)$ on NEFA concentrations throughout the study according to the ANOVA for repeated measures were observed.

\section{Health, Reproductive, and Productive Parameters of AIAO Cows with an Additional Pen Movement in the Prepartum Period}

A total of 18 cows $(7 \%)$ enrolled in the AIAO treatment did not calve within their replicate and had to be moved to a different pen. The interval from movement to a new pen and calving was $3.7 \pm 1.3 \mathrm{~d}$. Two cows calved on the same day they were moved, 2 cows calved on the day after being moved, 7 cows calved $2 \mathrm{~d}$ after being moved, 4 cows calved $3 \mathrm{~d}$ after being moved, 2 cows calved $7 \mathrm{~d}$ after being moved, and 1 cow calved 25 $\mathrm{d}$ after being moved.

Body condition scores at $0(P=0.51), 28(P=0.33)$, and $56(P=0.98)$ DIM were not different between

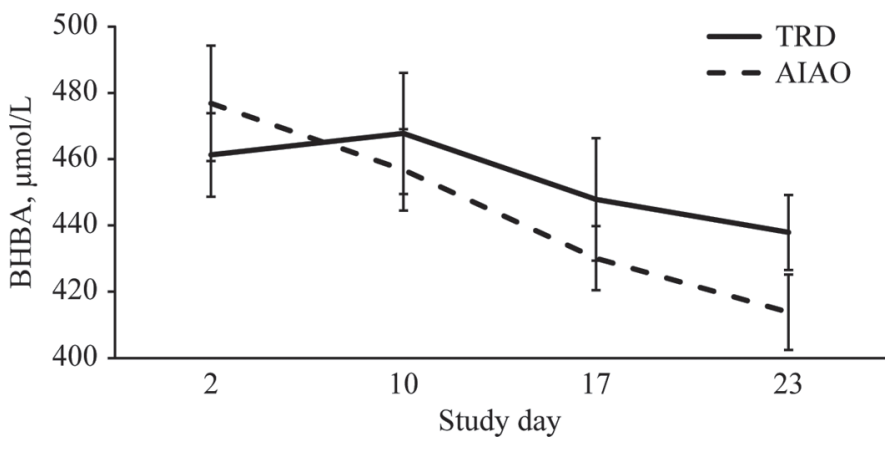

Figure 5. Raw means of plasma BHBA concentration of cows submitted to the traditional prepartum grouping strategy (TRD) and all-in-all-out (AIAO) prepartum grouping strategy. Bars represent the SEM calculated using the raw means. The TRD had weekly entry of new cows into the prepartum pen, and AIAO had no entry of new cows in the prepartum pen. Target stocking density was $100 \%$ of stalls and $91.6 \%$ of headlocks and $7.9 \mathrm{~m}^{2} /$ cow. No effects of treatment $(P=0.60)$ and of the interaction between treatment and study day $(P=0.71)$ on BHBA concentration throughout the study according to the ANOVA for repeated measures were observed.

AIAO cows that had to be moved to a different pen and those that calved within their replicate. The incidences of twinning $(P=0.51)$ and male calves $(P=0.51)$ were not different between AIAO cows that had to be moved to a different pen (twins $=0 \%$, male calf $=44.4 \%$ ) and those that calved within their replicate (twins $=$ $3.8 \%$, male calf $=47.5 \%)$. A tendency $(P=0.10)$ was observed for the incidence of retained fetal membranes to be reduced among AIAO cows that had to be moved to a different pen (0 vs. 12.5\%), but incidences of metritis $(P=0.73)$ and acute metritis $(P=0.64)$ were not different between AIAO cows that had to be moved to a different pen (metritis $=16.7 \%$, acute metritis $=$ $5.6 \%$ ) and AIAO cows that calved within their replicate (metritis $=20.1 \%$, acute metritis $=3.4 \%$ ). Similarly, incidence of DA (AIAO moved $=0 \%$, AIAO not moved $=1.8 \% ; P=0.74)$, incidence of mastitis (AIAO moved

Table 3. Effects of prepartum grouping strategy (TRD vs. AIAO) ${ }^{1}$ on resumption of ovarian cycles postpartum, estrus expression, and percentage of cows pregnant after first and second postpartum AI

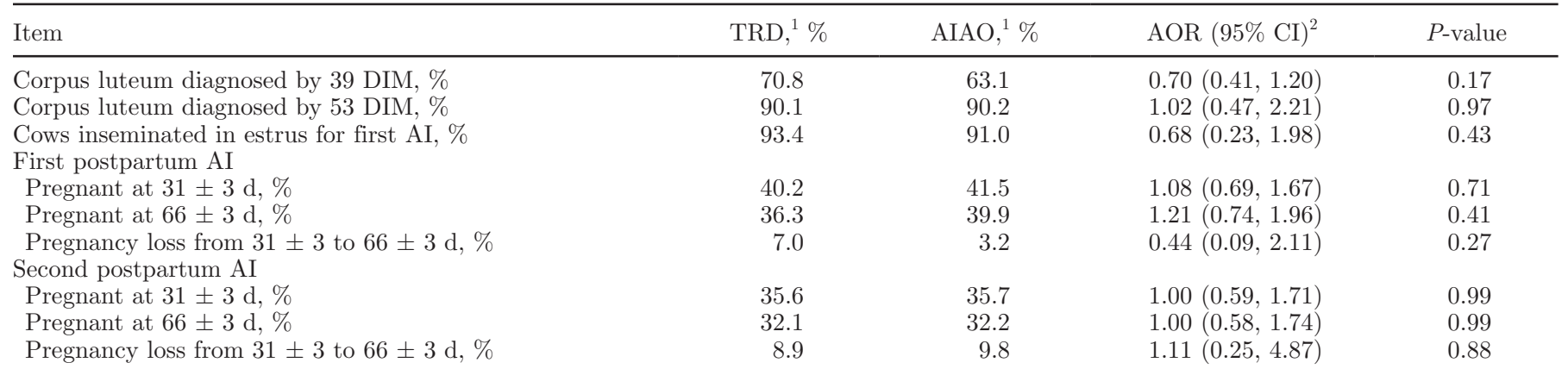

${ }^{1}$ Traditional prepartum grouping strategy $(\mathrm{TRD})$ = weekly entry of new cows into the prepartum pen; all-in-all-out prepartum grouping strategy $(\mathrm{AIAO})=$ no entry of new cows in the prepartum pen. Target stocking density was $100 \%$ of stalls and $91.6 \%$ of headlocks and $7.9 \mathrm{~m}^{2} /$ cow.

${ }^{2} \mathrm{AOR}=$ adjusted odds ratio. The TRD treatment was set as referent. 


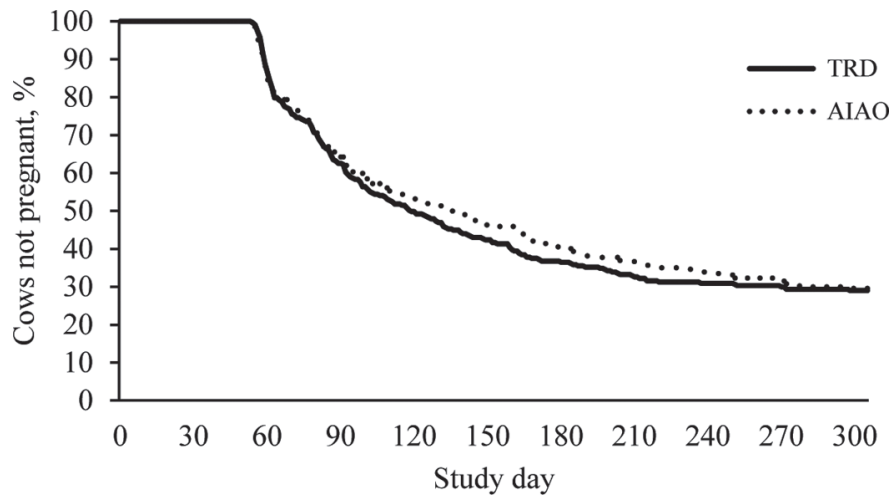

Figure 6. Survival analysis of interval from calving to establishment of pregnancy of cows submitted to the traditional prepartum grouping strategy (TRD) and all-in-all-out (AIAO) prepartum grouping strategy. The adjusted hazard ratio (AHR) for pregnancy was not $(P=0.49)$ different between AIAO [AHR $(95 \% \mathrm{CI})=1.07(0.88$, 1.30)] and TRD treatments. The TRD had weekly entry of new cows into the prepartum pen, and AIAO had no entry of new cows in the prepartum pen. Target stocking density was $100 \%$ of stalls and $91.6 \%$ of headlocks and $7.9 \mathrm{~m}^{2} /$ cow. The mean \pm SEM intervals from calving to establishment of pregnancy were $136.9 \pm 5.2 \mathrm{~d}$ for the TRD treatment and $132.7 \pm 5.0 \mathrm{~d}$ for the AIAO treatment.

$=0 \%$, AIAO not moved $=12.1 \% ; P=0.12$ ), and the percentage of cows removed from the herd within 60 DIM (AIAO moved $=5.6 \%$, AIAO not moved $=9.1 \%$; $P=0.61)$ were not different between AIAO cows that had to be moved to a different pen and AIAO cows that calved within their replicate. Similarly, the rate at which cows were removed from the herd was not $(P=0.64)$ different between AIAO cows that had to be moved to a different pen $[\mathrm{AHR}(95 \% \mathrm{CI})=1.28$ $(0.46,3.54)]$ and AIAO cows that calved within their replicate.

Cows in the AIAO treatment that had to be moved to a different pen were $(P=0.04)$ more likely to have a CL by 39 DIM than AIAO cows that calved within their replicate ( 88.2 vs. $61.2 \%$ ), but the percentage of cows with a CL by 53 DIM was not different (AIAO moved $=100 \%$, AIAO not moved $=89.5 \% ; P=0.97$. The AHR for pregnancy was not $(P=0.71)$ different between AIAO cows that had to be moved to a different

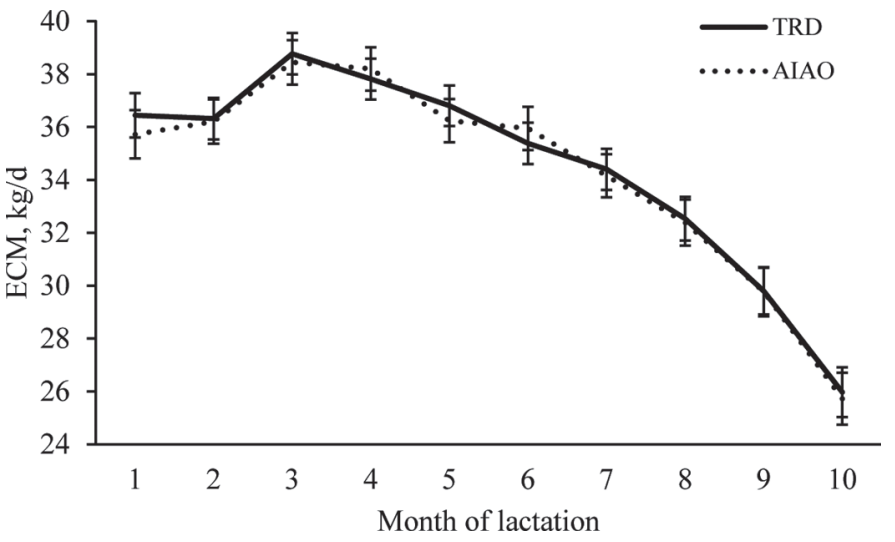

Figure 7. Yield of ECM according to prepartum grouping strategy [traditional prepartum grouping strategy (TRD) vs. all-in-all-out (AIAO) prepartum grouping strategy]. The TRD had weekly entry of new cows into the prepartum pen, and AIAO had no entry of new cows in the prepartum pen. Target stocking density was $100 \%$ of stalls and $91.6 \%$ of headlocks and $7.9 \mathrm{~m}^{2} /$ cow. No effect of treatment $(P=0.88)$ and of the interaction between treatment and month of lactation $(P=$ 0.98 ) on yield of ECM was observed.

pen $[$ AHR $(95 \% \mathrm{CI})=0.90(0.51,1.59)]$ and AIAO cows that calved within their replicate.

Milk yield was greater for AIAO cows that had to be moved to a different pen compared with AIAO cows that calved within their replicate (Table 5). Fat and protein yields were greater for AIAO cows that had to be moved to a different pen compared with AIAO cows that calved within their replicate (Table 5). Yields of $3.5 \% \mathrm{FCM}$ and ECM were greater for AIAO cows that had to be moved to a different pen compared with AIAO cows that calved within their replicate (Table 5). Finally, no differences were observed between AIAO cows that had to be moved to a different pen compared with AIAO cows that calved within their replicate in regards to linear SCC (Table 5).

\section{DISCUSSION}

The AIAO prepartum grouping strategy used in this experiment resulted in reduced stocking density

Table 4. Monthly productive parameters and milk quality up to $305 \mathrm{~d}$ postpartum of cows submitted to different prepartum grouping strategies (TRD vs. AIAO) ${ }^{1}$

\begin{tabular}{llcc}
\hline Item & \multicolumn{1}{c}{ TRD $^{1}$} & AIAO $^{1}$ & $P$-value \\
\hline Milk yield, $\mathrm{kg} / \mathrm{d}$ & $28.9 \pm 0.6$ & $28.9 \pm 0.6$ & 0.95 \\
Fat yield, kg/d & $1.30 \pm 0.02$ & $1.28 \pm 0.02$ & 0.72 \\
Protein yield, kg/d & $1.08 \pm 0.02$ & $1.07 \pm 0.02$ & 0.93 \\
$3.5 \%$ FCM yield, kg/d & $37.0 \pm 0.6$ & $36.7 \pm 0.6$ & 0.72 \\
ECM yield, kg/d & $34.4 \pm 0.6$ & $34.3 \pm 0.7$ & 0.88 \\
Linear SCC & $3.08 \pm 0.08$ & $2.96 \pm 0.08$ & 0.31 \\
\hline
\end{tabular}

${ }^{1}$ Traditional prepartum grouping strategy (TRD) = weekly entry of new cows into the prepartum pen; all-inall-out prepartum grouping strategy $(\mathrm{AIAO})=$ no entry of new cows in the prepartum pen. Target stocking density was $100 \%$ of stalls and $91.6 \%$ of headlocks and $7.9 \mathrm{~m}^{2} /$ cow. 
Table 5. Comparison of productive parameters and milk quality of $\mathrm{AIAO}^{1}$ cows that calved within their replicate and AIAO cows that had to be moved to a different pen

\begin{tabular}{lccc}
\hline Item & $\begin{array}{c}\text { AIAO that calved } \\
\text { within their replicate }\end{array}$ & $\begin{array}{c}\text { AIAO moved to } \\
\text { a different pen }\end{array}$ & $P$-value \\
\hline Milk yield, $\mathrm{kg} / \mathrm{d}$ & $28.1 \pm 0.47$ & $33.4 \pm 1.56$ & $<0.01$ \\
Fat yield, $\mathrm{kg} / \mathrm{d}$ & $1.25 \pm 0.02$ & $1.49 \pm 0.07$ & $<0.01$ \\
Protein yield, kg/d & $1.05 \pm 0.02$ & $1.25 \pm 0.05$ & $<0.01$ \\
$3.5 \% \mathrm{FCM}$ yield, $\mathrm{kg} / \mathrm{d}$ & $35.8 \pm 0.58$ & $42.6 \pm 1.91$ & $<0.01$ \\
$\mathrm{ECM}$ yield, $\mathrm{kg} / \mathrm{d}$ & $33.4 \pm 0.53$ & $39.7 \pm 1.73$ & $<0.01$ \\
Linear SCC & $2.94 \pm 0.08$ & $3.18 \pm 0.28$ & 0.41 \\
\hline${ }^{1}$ All-in-all-out prepartum grouping strategy (AIAO) $=$ no entry of new cows in the prepartum pen. Target \\
stocking density was $100 \%$ of stalls and $91.6 \%$ of headlocks and $7.9 \mathrm{~m}^{2} /$ cow.
\end{tabular}

compared with the TRD prepartum grouping strategy. Even though reduced stocking density may be a confounder that limits our ability to determine if grouping alone affects the parameters evaluated herein, this was an expected and unavoidable outcome because of the nature of the AIAO grouping strategy and because of the inherent variation in gestation length among cows.

The prepartum AIAO grouping strategy did not affect metabolic and health parameters of periparturient lactating dairy cows. The concentrations of NEFA and BHBA were slightly lower than the values reported for Holstein cows, but consistent with data from Jersey cows (Rastani et al., 2001; Guretzky et al., 2006). One of the hypotheses of the current experiment was that by reducing agonistic behavior among cows in the AIAO treatment we would improve metabolic parameters as a consequence of improved DMI, which would consequently result in improved health. Focal cows enrolled in the AIAO and TRD treatments were evaluated for displacement rate (events per cow per day) from the feed bunk during the first $3 \mathrm{~h}$ after feeding on $\mathrm{d} 1,2$, 3 , and 7 after regrouping on a weekly basis (Lobeck et al., 2012). As demonstrated by Lobeck et al. (2012), the displacement rate was reduced in the AIAO treatment compared with the TRD treatment. Thus, considering that the AIAO treatment reduced the rate of displacement from the feed bunk (Lobeck et al., 2012) and reduced the average stocking density (71.9 vs. $86.9 \%$ ) compared with the TRD treatment, the lack of differences between the AIAO and TRD prepartum grouping strategies on the incidence of postpartum disorders is somewhat surprising. In the current experiment, DMI was not measured because the study was conducted in a large commercial herd. Cows assigned to the AIAO and TRD treatments had similar concentrations of NEFA during the peripartum period and BHBA during the postpartum period, similar BCS from d -21 to 56 , and similar yields of ECM, which allows us to speculate that no differences in DMI and energy balance between the 2 treatments existed.
Coonen et al. (2011) observed no differences in prepartum NEFA concentration and DMI between cows submitted to a stable prepartum grouping strategy and cows that were exposed to regrouping twice weekly during the prepartum period. Conversely, von Keyserlingk et al. (2008) demonstrated that lactating dairy cows had reduced feeding time, increased number of displacement events from the feed bunk, and reduced milk yield within the first $2 \mathrm{~d}$ after pen movement. Schirmann et al. (2011) demonstrated that regrouping of prepartum cows housed in pens with 1 feed bin for every 2 cows resulted in reduced feed intake compared with feed intake before movement. Cows that were regrouped initiated more displacements from the feed bunk on the day of and the day after regrouping compared with cows that remained in the same pen (Schirmann et al., 2011). In the current experiment, AIAO cows that had to be moved to a different pen calved on average 3.7 $\mathrm{d}$ after pen movement and had greater yields of milk, ECM, and FCM compared with AIAO cows that calved within their replicate. Conclusions from the comparison of AIAO cows that had to be moved to a different pen and AIAO cows that calved within their replicate may be confounded because cows were not randomly allocated to these groups. Nonetheless, it is interesting to note that cows that calved within the period of greatest social unrest after movement (3.7 d after regrouping on average) apparently had no compromise of health, reproductive, and productive performances. Upon recognition of a stressor, animals first mount a biological response that may or may not eliminate the stressor and allow the animal to return to homeostasis (Moberg, 2000). Biological responses to a stressor may be neuroendocrine, autonomic, immune, or behavioral in nature (Moberg, 2000). The activation of specific biological responses depends on the stressor (Moberg, 2000). The duration of exposure to the stressor and the intensity and duration of the biological responses to the stressor determine alterations in biological functions and the occurrence of pathological processes (Moberg, 
2000). Therefore, it is not sufficient to evaluate only one biological response to stress. Furthermore, the interpretation of the importance of biological responses to stress must be made taking into consideration the changes in biological function and occurrence of pathological processes consequent to exposure to the stressor.

A subgroup of cows from the AIAO and TRD groups were evaluated weekly during the peripartum period for cortisol serum concentration and innate and humoral immune responses (Silva et al., 2012). No differences were observed between AIAO and TRD cows regarding cortisol concentration and innate and humoral immune parameters (Silva et al., 2012). These are important findings that may help explain why no differences were observed between the AIAO and TRD treatments regarding the incidence of postpartum diseases. Function of PMNL is fundamental for host defense (Cai et al., 1994) and is associated with occurrence of retained fetal membranes and metritis (Kimura et al., 2002; Hammon et al., 2006).

No effect of treatment was observed on the percentage of cows with locomotion score $>2$ at any interval after enrollment. In the experiment by von Keyserlingk et al. (2008), cows tended to spend fewer hours lying down on the day of regrouping compared with the day preceding the regrouping; but on the days following regrouping, lying time was not different than the lying time on the day preceding regrouping. The transient decrease in lying time following regrouping is unlikely to cause a significant increase in total standing time during the prepartum period, thus limiting the negative effects of regrouping on hoof health.

The reproductive performance of cows submitted to the AIAO and TRD prepartum grouping strategies was not different. Reproductive performance is affected by many physiological and pathological processes. It is well known that cows that undergo severe negative energy balance postpartum are more likely to be anovular for prolonged periods of time after calving (Butler, 2000), that cows that have a prolonged anovular period are less likely to conceive and have reduced pregnancy rates (Chebel and Santos, 2010; Galvão et al., 2010), and that cows with postpartum health disorders are less likely to conceive and have reduced pregnancy rates (Chebel and Santos, 2011). Considering that metabolic parameters, incidence of anovular condition, and incidence of health disorders were similar between AIAO and TRD cows, it is not surprising that no differences in reproductive performance were observed between AIAO and TRD cows.

Cows in the AIAO and TRD prepartum grouping strategy had similar milk yield. Furthermore, yield of fat and protein was similar between AIAO and TRD cows. Consequently, yield of 3.5\% FCM and ECM was not different between the AIAO and TRD prepartum grouping strategies. Similar to reproductive performance, productive performance is affected by several pathological processes. Chapinal et al. (2012) demonstrated that concentrations of NEFA $\geq 0.5 \mathrm{mEq} / \mathrm{L}$ and $\mathrm{BHBA} \geq 600 \mu \mathrm{mol} / \mathrm{L}$ during the week preceding parturition were associated with the most significant milk loss during approximately the first 4 mo of lactation. Treatment did not affect metabolic and health parameters; therefore, it is not surprising that productive parameters of AIAO and TRD cows were not different.

\section{CONCLUSIONS}

Metabolic parameters of Jersey cows submitted to the TRD or AIAO treatments were not different. Furthermore, prepartum grouping strategy did not affect the incidence of postpartum health disorders, the rate at which cows became pregnant, the rate at which cows were removed from the herd, or productive parameters. Even though the AIAO grouping strategy reduced unfavorable behaviors among Jersey cows and reduced the average stocking density during the prepartum period, it did not improve the performance of Jersey cows. Therefore, in situations of adequate stocking density and availability of feed bunk space as observed in the current experiment, the AIAO prepartum grouping strategy does not improve health or productive and reproductive parameters.

\section{ACKNOWLEDGMENTS}

The authors thank the owner, manager, and staff of New Sweden Dairy (Nicollet, MN). This experiment was partially funded by the Minnesota Agricultural Experiment Station (St. Paul) through the Rapid Agriculture Response Fund grant.

\section{REFERENCES}

Ballou, M. A., R. C. Gomes, S. O. Juchem, and E. J. DePeters. 2009 Effects of dietary supplemental fish oil during the peripartum period on blood metabolites and hepatic fatty acid compositions and total triacylglycerol concentrations of multiparous $\mathrm{HO}$ cows. J. Dairy Sci. 92:657-669.

Butler, W. R. 2000. Nutritional interactions with reproductive performance in dairy cattle. Anim. Reprod. Sci. 60-61:449-457.

Cai, T. Q., P. G. Weston, L. A. Lund, B. Brodie, D. J. McKenna, and W. C. Wagner. 1994. Association between neutrophil functions and periparturient disorders in cows. Am. J. Vet. Res. 55:934-943.

Chapinal, N., M. E. Carson, S. J. LeBlanc, K. E. Leslie, S. Godden, M. Capel, J. E. Santos, M. W. Overton, and T. F. Duffield. 2012. The association of serum metabolites in the transition period with milk production and early-lactation reproductive performance. J. Dairy Sci. 95:1301-1309.

Chebel, R. C., and J. E. Santos. 2011. Association between leptin single nucleotide polymorphism and reproductive performance of lactating Holstein cows. Anim. Reprod. Sci. 127:126-134. 
Chebel, R. C., and J. E. P. Santos. 2010. Effect of inseminating cows in estrus following a presynchronization protocol on reproductive and lactation performances. J. Dairy Sci. 93:4632-4643.

Cook, N. B., and K. V. Nordlund. 2004. Behavioral needs of the transition cow and considerations for special needs facility design. Vet. Clin. North Am. Food Anim. Pract. 20:495-520.

Coonen, J. M., M. J. Maroney, P. M. Crump, and R. R. Grummer. 2011. Short communication: Effect of a stable pen management strategy for precalving cows on dry matter intake, plasma nonesterified fatty acid levels, and milk production. J. Dairy Sci. 94:2413-2417.

Ferguson, J. D., D. T. Galligan, and N. Thomsen. 1994. Principal descriptors of body condition score in Holstein cows. J. Dairy Sci. 77:2695-2703.

Galvão, K. N., M. Frajblat, W. R. Butler, S. B. Brittin, C. L. Guard, and R. O. Gilbert. 2010. Effect of early postpartum ovulation on fertility in dairy cows. Reprod. Domest. Anim. 45:e207-211.

Goff, J. P., and R. L. Horst. 1997. Physiological changes at parturition and their relationship to metabolic disorders. J. Dairy Sci. 80:1260-1268

Grant, R. J., and J. L. Albright. 2001. Effect of animal grouping on feeding behavior and intake of dairy cattle. J. Dairy Sci. 84(ESuppl.):E156-E163

Guretzky, N. A., D. B. Carlson, J. E. Garrett, and J. K. Drackley. 2006. Lipid metabolite profiles and milk production for Holstein and Jersey cows fed rumen-protected choline during the periparturient period. J. Dairy Sci. 89:188-200.

Hammon, D. S., I. M. Evjen, T. R. Dhiman, J. P. Goff, and J. L. Walters. 2006. Neutrophil function and energy status in Holstein cows with uterine health disorders. Vet. Immunol. Immunopathol. 113:21-29.

Huzzey, J. M., D. M. Veira, D. M. Weary, and M. A. von Keyserlingk. 2007. Prepartum behavior and dry matter intake identify dairy cows at risk for metritis. J. Dairy Sci. 90:3220-3233.

Kasimanickam, R., T. F. Duffield, R. A. Foster, C. J. Gartley, K. E. Leslie, J. S. Walton, and W. H. Johnson. 2004. Endometrial cytology and ultrasonography for the detection of subclinical endometritis in postpartum dairy cows. Theriogenology 62:9-23.

Kimura, K., J. P. Goff, M. E. Kehrli Jr., J. A. Harp, and B. J. Nonnecke. 2002. Effects of mastectomy on composition of peripheral blood mononuclear cell populations in periparturient dairy cows. J. Dairy Sci. 85:1437-1444.

LeBlanc, S. 2010. Monitoring metabolic health of dairy cattle in the transition period. J. Reprod. Dev. 56:S29-S35.

Lobeck, K. M., M. I. Endres, P. R. B. Silva, and R. C. Chebel. 2012. Effect of prepartum grouping strategy on agonistic behavior of dairy cows. J. Dairy Sci. 95(Suppl. 2):219.

McDougall, S., R. Macaulay, and C. Compton. 2007. Association between endometritis diagnosis using a novel intravaginal device and reproductive performance in dairy cattle. Anim. Reprod. Sci. 99:9-23.

Moberg, G. P. 2000. Biological response to stress: Implications for animal welfare. Pages 1-21 in The Biology of Animal Stress: Basic Principles and Implications for Animal Welfare. G. P. Moberg and J. A. Mench, ed. CABI Publishing, New York, NY.

Orth, R. 1992. Sample day and lactation report. In Dairy Herd Improvement Association 200 Fact Sheet A-2. M. S. DRPC, ed, Ames, IA.

Rastani, R. R., S. M. Andrew, S. A. Zinn, and C. J. Sniffen. 2001 Body composition and estimated tissue energy balance in Jersey and Holstein cows during early lactation. J. Dairy Sci. 84:12011209 .

Schirmann, K., N. Chapinal, D. M. Weary, W. Heuwieser, and M. A. G. von Keyserlingk. 2011. Short-term effects of regrouping on behavior of prepartum dairy cows. J. Dairy Sci. 94:2312-2319.

Silva, P. R. B., J. G. N. Moraes, L. G. D. Mendonça, A. A. Scanavez, G. Nakagawa, M. I. Endres, M. A. Ballou, and R. C. Chebel. 2012. Effects of prepartum grouping strategy on immune parameters of peripartum dairy cows. J. Dairy Sci. 95(Suppl. 2):43.

Sprecher, D. J., D. E. Hostetler, and J. B. Kaneene. 1997. A lameness scoring system that uses posture and gait to predict dairy cattle reproductive performance. Theriogenology 47:1179-1187.

von Keyserlingk, M. A. G., D. Olenick, and D. M. Weary. 2008. Acute behavioral effects of regrouping dairy cows. J. Dairy Sci. 91:10111016

Zelena, D., J. Haller, and J. Halasz. 1999. Social stress of variable intensity: Physiological and behavioural consequences. Brain Res. Bull. 48:297-302. 